\title{
Anti-Annexin V and Cardiovascular Risk Factors in Systemic Lupus Erythematosus
}

\author{
Zahra Rezaieyazdi $^{*}$, Fatemeh Hajizadeh-Saffar ${ }^{1}$, Sima Sedighi ${ }^{2}$, Hassan Mansouritorghabeh ${ }^{3}$ \\ ${ }^{1}$ Rheumatic Diseases Research Center, Mashhad University of Medical Sciences, Mashhad, Iran. ${ }^{2}$ Rheumatology \\ Research Centre (RRC), Golestan University of Medical Sciences, Gorgan, Iran. ${ }^{3}$ Immunology Research Center, In- \\ flammation and inflammatory diseases Division, Mashhad University of Medical Sciences, Mashhad, Iran.
}

\begin{abstract}
Background and Objective: Anti-annexin V has been proposed as a novel mechanism for the increased prevalence of atherosclerosis among patients with systemic lupus erythematosus (SLE). This study aimed to compare anti-annexin V levels between SLE patients and healthy controls and determine the correlation of anti-annexin with various cardiovascular risk factors.

Materials and Method: Sixty SLE patients and 30 healthy gender- and age-matched individuals were selected from outpatient rheumatology clinics in the city of Mashhad, Iran, and included in this cross-sectional study. Anti-annexin V and other parameters (including cardiovascular risk factors such as age, smoking, blood pressure, diabetes mellitus, lipoproteins levels, previous history of documented or clinically suspected atherosclerosis, obesity, premature ovarian failure, high sensitive C-reactive protein, vascular cell adhesion protein 1 and homocysteine) were measured using enzyme-linked immuno-assay.

Results: Anti-annexin V had a significant positive correlation with LDL levels $(\mathrm{p}=0.03, \mathrm{r}=0.28)$. Anti-annexin $\mathrm{V}$ levels were not significantly different between the two groups $(\mathrm{p}=0.40)$.

Conclusion: The role of anti-annexin $\mathrm{V}$ as a predictor of atherosclerosis risk in the lupus patients under study herein could not be confirmed.
\end{abstract}

Keywords: Annexin V, Cardiovascular Diseases, Risk Factors, Systemic Lupus Erythematosus

\section{Introduction}

Systemic Lupus Erythematosus (SLE) is an autoimmune connective tissue disease with involvement of various organs in the body. In SLE, the immune system attacks cells and tissues of the body, resulting in tissue damage and inflammation $[1,2]$. Both types II and III hypersensitivity reactions are involved in the pathogenesis of this disease $[3,4]$. SLE most often harms the joints, blood vessels, kidneys, nervous system, heart, skin, liver, and lungs [5, 6]. The incidence of SLE is about 9 times higher in females. Moreover, it is more common in ages between 1535 years $[4,7]$. SLE can be a fatal disease; the main cause of mortality in the long-term is cardiovascular disease related to atherosclerosis [8-10]. With recent developments in knowledge about the pathophysiology of SLE and improved diagnosis and treatment methods, life expectancy and quality of life in SLE patients have improved [11]. On the other side of the coin, due to increased life span and overall improvement in the prognosis of SLE patients, new complications have emerged [12]. Cardiovascular complications are among risk factors that influence morbidity and mortality rates in patients with SLE. It has become clear that its incidence is about 2.6-20\% compared with genderand age-matched persons without SLE [7, 13-15].

Annexin $\mathrm{V}$ is a ubiquitous protein with 320 amino acids, a weight of $36 \mathrm{KDa}$, and its relevant gene is located on 4 q26-q28 with 13 exons and 12 introns $[16,17]$. Annexin $\mathrm{V}$ has wide tissue distribution, including the striated muscles of the heart, vascular endothelium, chondrocytes, placenta, osteoblast, hepatocytes, and so on [18-20]. It plays a key role in the regulation of apoptosis by binding to the phosphatidylserine-exposing apoptotic cells and impeding their pro-coagulant and proinflammatory actions. It exerts anticoagulant activity as an inhibitor of the prothrombin activation process $[21,22]$.

Antibodies (Abs) against annexin $\mathrm{V}$ have been addressed in patients with SLE [23]. It has been proposed that the increased apoptosis mechanism leads to antigenic stimulation by extracellular/membrane exposition to the immune system, leading to the production of autoantibodies [24]. These Abs can interfere with functional sites of annexin $\mathrm{V}$ and also make immune complex, leading to a lower half-life of annexin $\mathrm{V}$ in plasma. These Abs are connected to the recurrent abortions and thrombotic episodes in SLE [25-27]. Anti-an-

Personal non-commercial use only.Rheumatology Research Journal. Copyright $@$ 2019. All rights reserved

*Corresponding Author: Zahra Rezaieyazdi, MD. Rheumatic Diseases Research Center, Mashhad University of Medical Sciences, Mashhad. Iran. Tel: +985138012753 E-mail: Rezaieyazdiz@mums.ac.ir

Received: 17 July 2019; Accepted: 08 March 2020 
nexin $\mathrm{V}$ antibodies also inhibit the binding of annexin $\mathrm{V}$ to endothelium, thus inducing atherothrombosis.

Results regarding the influence of anti-annexin $\mathrm{V}$ antibodies on thromboembolic events in SLE, in addition to other pro-thrombotic factors, are controversial [28]. The current study evaluated possible relations between anti-annexin $\mathrm{V}$ antibody and some cardiovascular disease risk factors in patients with SLE and controls.

\section{Materials and Methods}

This cross-sectional study was conducted on 90 individuals, 60 of whom were lupus patients and formed the patient group and 30 individuals who formed the control group. Patients in the case group were selected from outpatient rheumatology clinics at Ghaem University hospitals in the city of Mashhad. The lupus group fulfilled the diagnostic criteria of the American College of Rheumatology [29] with a disease duration of at least one year. Individuals who did not fulfill the ACR criteria for SLE diagnosis and those who had another connective tissue disease, renal failure, recent infection, or malignancy were excluded from the study. The control group included 30 persons who matched by age and gender with the case group and were selected from individuals referring to our clinics for mechanical and non-specific pain. Informed consent was obtained from all participating patients and healthy controls.

The cardiovascular risk factors taken into account in this study comprised being older than 55 years of age, recent smoking (in the recent 10 years), blood pressure greater than $140 / 90$ or the use of antihypertensive medication, diabetes mellitus, high density lipoprotein (HDL) levels (lower than $40 \mathrm{mg} / \mathrm{dl}$ for men and $50 \mathrm{mg} / \mathrm{dl}$ for women), low density lipoprotein (LDL) levels (higher than $160 \mathrm{mg} / \mathrm{dl}$ ), previous history of documented or clinically suspected atherosclerotic disease (i.e. myocardial infarction, angina pectoris, coronary artery bypass graft, angioplasty, or stroke), peripheral artery disease, claudication and evidence of premature atherosclerosis (increased intima media thickness [IMT]) in ultrasound imaging of the carotid artery), obesity (Body Mass Index greater than 30), premature ovarian failure (younger than 45 years), high sensitive C-reactive protein (hs-CRP), vascular cell adhesion protein 1 (VCAM1) and homocysteine. Detection of antibodies against annexin was done using enzyme-linked immuno-sorbent assay (ELISA) kit (Bender MedSystem, Vienna, Austria) with adherence to the manufacturer's instruction.

The American College of Rheumatology's SLEDAI-2000 form was completed for each patient and their scores were calculated pursuant to its mandate. Further information about history of cardiac problems and risk factors was obtained using a questionnaire, physical examination, medical records, and if necessary, electrocardiography or echocardiography was carried out. Doppler ultrasound imaging of left and right common carotid was performed, determining the presence of plaque and intima media thickness (IMT).

Information from individuals in the control group about history of cardiac problems and risk factors was obtained using a questionnaire, physical examination, evaluation of possible health records in our clinic, and in some cases, electrocardiography or echocardiography was carried out. Carotid artery ultrasound imaging was also performed.

\section{Statistical Analysis}

The Kolmogorov-Smirnov test was used to assess the normality of data. For data with normal distribution, the student's t-test was applied. Descriptive analysis was shown as mean \pm standard. Raw data was analyzed using SPSS version 11.5 (Chicago, IL, USA). Correlations between variables were examined using Pearson's correlation coefficient. The Mann-Whitney U test was used to assess non-normal data. A p-value of 0.05 was considered statistically significant.

This study conformed to the principles outlined in the Declaration of Helsinki. The Organizational Ethics Committee of Mashhad University of Medical Sciences also approved this study (No. 6662).

\section{Results}

The average participant age was $32.06 \pm 8.90(\mathrm{SD})$ years for the patient group and $34.19 \pm 6.46$ (SD) years for the control group. Using the Kolmogorov-Smirnov assay, it was determined that the distribution of age in both groups was normal. The independent samples t-test showed that the two groups were matched for age $(\mathrm{p}=0.062)$. There were 5 males in the patient group and 4 males in the control group. The chi-square assay showed that the two groups were matched for gender $(p=0.47)$. Disease activity was assessed using ACR's SLEDAI-2000 score. The patient group had a minimum SLEDAI of zero and a maximum of thirty-one. Active disease was defined as SLEDAI $>4$, while very active disease was defined as SLEDAI $>10$ [4]. Among the patients, $30(50 \%)$ had inactive disease, $14(22.3 \%)$ had active disease, and 16 (24.7\%) had very active disease.

The mean value of anti-annexin $\mathrm{V}$ in the patient group was $0.1661 \pm 0.55 \mathrm{ng} / \mathrm{ml}$, with a minimum of 0 and a maximum of $3.7 \mathrm{ng} / \mathrm{ml}$. The mean value for anti-annexin $\mathrm{V}$ in the control group was $0.45 \pm 1.5 \mathrm{ng} / \mathrm{ml}$, with a minimum of 0 and a maximum of $7.8 \mathrm{ng} / \mathrm{ml}$. The Mann-Whitney assay showed no significant difference between the two groups $(\mathrm{p}=0.93)$.

A significant positive correlation was found between LDL and anti-annexin $\mathrm{V}$ levels $(\mathrm{p}=0.03, \mathrm{r}=0.28)$. LDL levels were significantly different between the patient and control groups $(\mathrm{p}<0.001)$, but anti-annexin $\mathrm{V}$ levels were not significantly different between the two groups $(p=0.40)$. Subjects with a history of cardiovascular complications or 
evidence of atherosclerosis in carotid ultrasound were so small in number ( 5 cases in each category) as to make analysis meaningless. However, the levels of the anti-annexin $\mathrm{V}$ and LDL, (as well-established risk factors for atherosclerosis) were determined to be significant in the patient group. Anti-annexin V levels were not significantly correlated with any other evaluated risk factor in either the patient or the control group (Table 1). Other variables were taken into account in this study, including history of CVA, peripheral artery disease, history of angioplasty, history of angina pectoris or MI, history of premature ovarian failure, smoking, diabetes mellitus, presence of anti-phospholipid, and gender. However, the number of subjects positive for each of these variables was so small as to make statistical analysis meaningless.

It must be noted that among the 5 patients who had atherosclerotic plaque in the carotid, there was one case of high anti-annexin V $(0.6 \mathrm{ng} / \mathrm{ml})$. Furthermore, among the 5 patients who were positive for anti-phospholipid antibodies, there was one case with high anti-annexin $\mathrm{V}(1.5 \mathrm{ng} / \mathrm{ml})$.

\section{Discussion}

Annexins are a heterogenous group of twelve proteins which are involved in various cell processes, including growth and apoptosis. Autoantibodies directed to several forms of annexin (including annexin V) have been reported, but their function and clinical relevance are controversial. Anti-annexin V antibodies were found in patients with autoimmune rheumatic diseases such as SLE, primary antiphospholipid syndrome, or systemic sclerosis who present with arterial or venous thrombosis. Annexin V have a high affinity for phospholipids that play an essential role in the regulation of coagulation. Anti-annexin $\mathrm{V}$ antibody also inhibit the binding of annexin $\mathrm{V}$ to endothelium, which may induce atherothrombosis. There are controversial results suggesting that anti-annexin $\mathrm{V}$ antibodies could be associated with thromboembolic and atherothrombotic events in lupus patients [28].

As stated in the results section, the current study could not confirm the role of anti-annexin $\mathrm{V}$ as a predictor of atherosclerosis risk in patients with lupus.

Despite a marked difference between the two groups re-

Table 1. The Spearman's correlation of studied risk factors with anti-annexin V levels in the Lupus group and controls.

\begin{tabular}{|c|c|c|}
\hline \multicolumn{3}{|c|}{ p-value } \\
\hline Markers & $\begin{array}{l}\text { Lupus group } \\
\text { r }_{s}(p-v a l u e)\end{array}$ & $\begin{array}{c}\text { control group } \\
\mathbf{r}_{s}(p-v a l u e)\end{array}$ \\
\hline VCAM1 & $-0.039(0.769)$ & $-0.122(0.536)$ \\
\hline Age & $-0.053(0.690)$ & $0.074(0.712)$ \\
\hline BMI & $0.162(0.221)$ & $0.096(0.626)$ \\
\hline SLE duration & $0.182(0.167)$ & - \\
\hline Right Superior IMT & $0.020(0.883)$ & $-0.079(0.696)$ \\
\hline Right Inferior IMT & $0.106(0.424)$ & $0.127(0.526)$ \\
\hline Left Superior IMT & $-0.146(0.269)$ & $0.040(0.848)$ \\
\hline Left Inferior IMT & $0.055(0.677)$ & $0.020(0.925)$ \\
\hline hs-CRP & $0.030(0.819)$ & $-0.281(0.147)$ \\
\hline homocystein & $-0.005(0.969)$ & $-0.197(0.316)$ \\
\hline Fasting Blood Sugar & $-0.015(0.913)$ & $-0.089(0.651)$ \\
\hline Triglyceride & $-0.089(0.651)$ & $-0.267(0.169)$ \\
\hline Total Cholesterol & $0.097(0.466)$ & $0.46(0.817)$ \\
\hline HDL & $0.104(0.432)$ & $0.233(0.233)$ \\
\hline LDL & $0.089(0.505)$ & $0.054(0.785)$ \\
\hline
\end{tabular}

IMT: intima media thickness, VCAM1: vascular cell adhesion protein 1, BMI: body mass index, SLE: systemic lupus erythematosus, hs-CRP: high sensivity C-reactive protein, HDL: high density lipoprotein, rs: Spearman's correlation. 
garding cardiovascular risk factors, anti-annexin $\mathrm{V}$ levels were not significantly different.

Nor were they significantly correlated with any traditional or novel cardiovascular risk factors studied in either group, except LDL cholesterol.

There was a significant positive correlation between LDL and anti-annexin $\mathrm{V}$ levels that is comparable with the results of a survey by van Tits LJ et al. [30], who demonstrated that, unlike oxidized LDL (oxLDL), annexin V levels dropped as carotid stenosis progressed. Their control group had the lowest oxLDL and highest annexin $\mathrm{V}$ levels. They proposed that the oxLDL-to-annexin ratio can be regarded as a new and effective marker for the presence and severity of atherosclerotic carotid stenosis.

Cederholm et al. showed that lupus patients with a positive history of cardiovascular disease showed a decrease in the junction of annexin $\mathrm{V}$ to the surface of endothelial cells. This connection was mediated by autoantibodies among anti-cardiolipin IgG. There was also a positive correlation between annexin $\mathrm{V}$ attachment and intima media thickness (IMT) in their patients. The authors proposed reducing the connection of annexin $\mathrm{V}$ to endothelium as a new system for atherothrombosis in patients with SLE [26]. Roldan et al. further showed that plasma levels of anti-annexin V were significantly lower in young patients suffering from myocardial infarction, which can indicate a hypercoagulability state independent from the existence of anti-phospholipid antibodies [27]. In their survey, Shojaie et al. demonstrated that low annexin $\mathrm{V}$ levels and positive anti-annexin $\mathrm{V}$ is correlated to an increased tendency for thrombosis not accounted for by traditional cardiovascular risk factors [25]. Pompilian et al. found that serum annexin A5 levels in the SLE group were independent predictors for IMT and endothelial dysfunction [31]. Anti-annexin V levels were not significantly correlated with intima media thickness (IMT) in the patients under survey in the current study.

Certainly, increased risk of vascular outcomes in patients with SLE may be multifactorial and may not completely mimic traditional cerebrovascular and cardiovascular episodes. Risk factors such as hyperglycemia, hypercholesterolemia and hypertension due to renal involvement or treatment with corticosteroids, endothelial damage due to immune-complexes, thrombosis due to anti-phospholipid antibodies, vasculitis, and Libman-Sacks endocarditis may be among casual factors that play a role in cardiovascular events in SLE patients. One limitation of the current study was the exclusion of patients with renal involvement.

\section{Conclusion}

Considering the results of the present study, the role of anti-annexin $\mathrm{V}$ as a potential predictor for atherosclerosis risk in lupus patients remains ambiguous. Studies with larger patient groups and meta-analyses may aid in confirming the issue.

\section{Addendum}

Z. Rezaieyazdi participated in study design, patient referral, interpretation of data, intellectual content revision, and approval of the final version of the manuscript.

F. Hajizadeh-Saffar wrote the primary draft of the manuscript and participated in following up the procedure and data analysis.

S. Sedighi assisted in referring patients and gathering data.

H. Mansouritorghabeh participated in laboratory analysis of anti-annexin $\mathrm{V}$ and in writing the manuscript.

\section{Source of Funding}

This study was given financial support by Mashhad University of Medical Sciences under grant number [89097].

\section{Acknowledgements}

The authors would like to thank the Vice Chancellor of Research at Mashhad University of Medical Sciences for the financial support; Dr. Azarpajooh, Department of Neurology, Mashhad University of Medical Science, Mashhad, Iran, for performing the Doppler sonography and assessing the intima-media thickness; and Dr. H. Esmaily, PhD in Statistics, Center for Health Sciences Research, School of Health, Mashhad University of Medical Sciences, Mashhad, for his kind participation in the statistical analysis.

\section{Conflict of Interests}

Authors affirm they have no conflicts of interest with regard to the current manuscript. 


\section{References}

1. Anselm Mak1, Nien Yee Kow, Herbert Schwarz, Lingli Gong, Sen Hee Tay, Lieng Hsi Ling. Endothelial dysfunction in systemic lupus erythematosus - a case-control study and an updated meta-analysis and meta-regression. Scientific Reports. 2017; 7:7320.

2. GC Tsokos, MS Lo, PC Reis, KE Sullivan. New insights into the immunopathogenesis of systemic lupus erythematosus. Nature Reviews Rheumatology. 2016; 12: 716-730.

3. Pradhan V, Rajadhyaksha A, Yadav K, Surve P, Patwardhan $\mathrm{M}$, Dhavale N. et al. Anti-C reactive protein antibodies in Indian patients with systemic lupus erythematosus. Indian J Nephrol 2013; 23(6):434. doi: 10.4103/09714065.120341

4. Rezaieyazdi Z, Sahebari M, Hatef M, Abbasi B, Rafatpanah H, Afshari JT. et al. Is there any correlation between high sensitive CRP and disease activity in systemic lupus erythematosus? Lupus 2011; 20(14):1494-500. doi: $10.1177 / 0961203311418706$

5. Ni J, Qiu L, Hu L, Cen H, Zhang M, Wen P. et al. Lung, liver, prostate, bladder malignancies risk in systemic lupus erythematosus: evidence from a meta-analysis. Lupus 2014; 23(3):284-92. doi: 10.1177/0961203313520060

6. Ziemer M, Milkova L, Kunz M. Lupus erythematosus. Part II: Clinical picture, diagnosis and treatment. $\boldsymbol{J}$ Deutsch Dermatol Ges 2014; 12(4):285-302. doi: 10.1111/ ddg. 12254

7. Manzi S, Meilahn EN, Rairie JE, Conte CG, Medsger TA, Jansen-McWilliams L. et al. Age-specific incidence rates of myocardial infarction and angina in women with systemic lupus erythematosus: comparison with the Framingham Study. Am J Epidemiol 1997; 145(5):408-15. doi: 10.1093/oxfordjournals.aje.a009122

8. M Wigren, E Svenungsson, IY Mattisson, JT Gustafsson et al. Cardiovascular disease in systemic lupus erythematosus is associated with increased levels of biomarkers reflecting receptor-activated apoptosis.

9. Bacon P, Stevens R, Carruthers D, Young S, Kitas G. Accelerated atherogenesis in autoimmune rheumatic diseases. Autoimmun Rev 2002; 1(6):338-47. doi: 10.1016/ s1568-9972(02)00100-3

10. Esdaile JM, Abrahamowicz M, Grodzicky T, Li Y, Panaritis C, Berger RD. et al. Traditional Framingham risk factors fail to fully account for accelerated atherosclerosis in systemic lupus erythematosus. Arthritis Rheum 2001; 44(10):2331-37. doi: 10.1002/1529-0131(200110)44:10< 2331::aid-art395>3.0.co;2-i

11. Anolik J. B cell biology: implications for treatment of systemic lupus erythematosus. Lupus 2013; 22(4):342-49. doi: 10.1177/0961203312471576

12. Bruce I, Urowitz M, Gladman D, Hallett D. Natural history of hypercholesterolemia in systemic lupus erythematosus. J Rheumatol 1999; 26(10):2137-43.

13. Cederholm A, Frostegård J. Annexin A5 in cardiovas- cular disease and systemic lupus erythematosus. Immunobiology 2005; 210(10):761-68. doi: 10.1016/j.imbio.2005.10.007

14. Petri M, Perez-Gutthann S, Spence D, Hochberg MC. Risk factors for coronary artery disease in patients with systemic lupus erythematosus. Am J Med 1992; 93(5):513-19. doi: 10.1016/0002-9343(92)90578-y

15. Bruce IN, Gladman DD, Urowitz MB. Premature atherosclerosis in systemic lupus erythematosus. Rheum Dis Clin North Am 2000; 26(2):257-78. doi: 10.1016/s0889857x(05)70138-1

16. Huber R, Berendes R, Burger A, Luecke H, Karshikov A. Annexin V-crystal structure and its implications on function. Behring Inst Mitt 1992(91):107-25.

17. Cookson BT, Engelhardt S, Smith C, Bamford HA, Prochazka M, Tait JF. Organization of the human annexin V (ANX5) gene. Genomics 1994; 20(3):463-67. doi: 10.1006/geno.1994.1201

18. Giambanco I, Pula G, Ceccarelli P, Bianchi R, Donato R. Immunohistochemical localization of annexin $\mathrm{V}(\mathrm{CaBP} 33)$ in rat organs. J Histochem Cytochem 1991; 39(9):1189-98. doi: $10.1177 / 39.9 .1833446$

19. Spreca A, Rambotti MG, Giambanco I, Pula G, Bianchi $\mathrm{R}$, Ceccarelli P. et al. Immunocytochemical localization of annexin $\mathrm{V}$ (CaBP33), a Ca2+-dependent phospholipid-and membrane-binding protein, in the rat nervous system and skeletal muscles and in the porcine heart. J Cell Physiol 1992; 152(3):587-98. doi: 10.1002/jcp.1041520319

20. Doubell AF, Lazure C, Charbonneau C, Thibault G. Identification and immunolocalisation of annexins V and VI, the major cardiac annexins, in rat heart. Cardiovasc Res 1993; 27(7):1359-67. doi: 10.1093/cvr/27.7.1359

21. Reutelingsperger C, Van Heerde W. Annexin V, the regulator of phosphatidylserine-catalyzed inflammation and coagulation during apoptosis. Cell Mol Life Sci 1997; 53(6):527-32. doi: 10.1007/s000180050067

22. Ravassa S, Bennaghmouch A, Kenis H, Lindhout T, Hackeng T, Narula J. et al. Annexin A5 down-regulates surface expression of tissue factor a novel mechanism of regulating the membrane receptor repertoir. J Biol Chem 2005; 280(7):6028-35. doi: 10.1074/jbc.M411710200

23. Hrycek A, Cieślik P. Annexin A5 and anti-annexin antibodies in patients with systemic lupus erythematosus. Rheumatol Int 2012; 32(5):1335-42. doi: 10.1007/ s00296-011-1793-2

24. Nakamura N, Shidara Y, Kawaguchi N, Azuma C, Mitsuda N, Onishi S. et al. Lupus anticoagulant autoantibody induces apoptosis in umbilical vein endothelial cells: involvement of annexin V. Biochem Biophys Res Commun 1994; 205(2):1488-93. doi: 10.1006/bbrc.1994.2833

25. Shojaie M, Sotoodah A, Roozmeh S, Kholoosi E, Dana S. Annexin V and anti-Annexin V antibodies: two interesting aspects in acute myocardial infarction. Thromb $\boldsymbol{J}$ 2009; 
7(1):13. doi: 10.1186/1477-9560-7-13

26. Cederholm A, Svenungsson E, Jensen-Urstad K, Trollmo C, Ulfgren A-K, Swedenborg J. et al. Decreased Binding of Annexin V to Endothelial Cells A Potential Mechanism in Atherothrombosis of Patients With Systemic Lupus Erythematosus. Arterioscler Thromb Vas Biol 2005; 25(1):198203.doi: 10.1161/01.ATV.0000150415.18759.36

27. Roldán V, Marín F, Pineda J, Marco P, Corral J, Climent $\mathrm{V}$. et al. Annexin V levels in survivors of early myocardial infarction. Rev Exp Cardiol 2002; 55(12):1230-34. doi: 10.1016/s0300-8932(02)76794-8

28. Iaccarino L, Ghirardello A, Canova M, Zen M, Bettio S, Nalotto L, Punzi L, Doria A. Anti-annexins autoantibodies: Their role as biomarkers of autoimmune diseases. $\boldsymbol{A u}$ toimmunity Reviews. 2011; 10: 553-558.
29. 1997 Update of Revised Systemic Lupus Erythematosus. 1997 Update of the 1982 American College of Rheumatology Revised Criteria for Classification of Systemic Lupus Erythematosus: American College of rheumatology.

30. van Tits LJ, van Heerde WL, van der Vleuten GM, de Graaf J, Grobbee DE, van de Vijver LP, Stalenhoef AF, Princen HM. Plasma annexin A5 level relates inversely to the severity of coronary stenosis. Biochemical and biophysical research communications. 2007; 356: 674-80.

31. Valer P, Paul B, Eugenia B, Camelia B. Annexin A5 as independent predictive biomarker for subclinical atherosclerosis and endothelial dysfunction in systemic lupus erythematosus patients. Clinical laboratory. 2012; 59: 359-67. 